\title{
Concept for a hyperspectral remote sensing algorithm for floating marine macro plastics
}

\author{
Lonneke Goddijn-Murphy ${ }^{\mathrm{a}, *}$, Steef Peters ${ }^{\mathrm{b}}$, Erik van Sebille ${ }^{\mathrm{c}, \mathrm{d}}$, Neil A. James ${ }^{\mathrm{a}}$, Stuart Gibb \\ a Environmental Research Institute, UHI-NHC, Thurso, Scotland, United Kingdom \\ ${ }^{\mathrm{b}}$ Water Insight BV, Wageningen, The Netherlands \\ ${ }^{\mathrm{c}}$ Institute for Marine and Atmospheric Research, Utrecht University, Utrecht, The Netherlands \\ ${ }^{\mathrm{d}}$ Grantham Institute, Imperial College London, London, United Kingdom
}

\section{A R T I C L E I N F O}

\section{Keywords:}

Plastic debris

Remote sensing

Marine environment

Pollution

\begin{abstract}
A B S T R A C T
There is growing global concern over the chemical, biological and ecological impact of plastics in the ocean. Remote sensing has the potential to provide long-term, global monitoring but for marine plastics it is still in its early stages. Some progress has been made in hyperspectral remote sensing of marine macroplastics in the visible (VIS) to short wave infrared (SWIR) spectrum. We present a reflectance model of sunlight interacting with a sea surface littered with macro plastics, based on geometrical optics and the spectral signatures of plastic and seawater. This is a first step towards the development of a remote sensing algorithm for marine plastic using light reflectance measurements in air. Our model takes the colour, transparency, reflectivity and shape of plastic litter into account. This concept model can aid the design of laboratory, field and Earth observation measurements in the VIS-SWIR spectrum and explain the results.
\end{abstract}

\section{Background}

Marine plastic litter is a global environmental problem that is of increasing concern (Rochman et al., 2016). Global plastic production increases annually (Andrady and Neal, 2009), with an estimated 4.8 to 12.7 million metric tons of plastic entering the oceans each year (Jambeck et al., 2015), posing a threat to seabirds (Wilcox et al., 2015), fish (Gregory, 2009), turtles (Mrosovsky et al., 2009) and marine mammals (Laist, 1997). However, there are still many questions about its sources, sinks, pathways, and trends in abundance of marine plastic litter, its harmful impacts on human and marine life, and the effectiveness of potential clean-up operations. Some surveys have been undertaken (e.g., Eriksen et al., 2014) but there is a lack of long-term, large scale monitoring. Remote sensing (RS) has the potential to provide long-term, global monitoring of floating marine plastics but is still in its infancy (Maximenko et al., 2016). In this paper, we describe a concept RS method for marine plastic litter floating on top of the sea surface, based on geometrical optics and the spectral signatures of plastic and seawater. The objective is to find a method that can derive the surface fraction of plastic floating on the sea surface from the measured reflectance of natural daylight in air. Asner (2016) has made some progress in the remote sensing of marine macroplastics in the visible (VIS) to short wave infrared (SWIR) spectrum and we base our modelling and experimental work on their reflectance spectra. VIS ranges from 400 to $780 \mathrm{~nm}$, SWIR from 1.1 to $3 \mu \mathrm{m}$, and NIR (near infrared) represents the wavelengths in between.

Addressing questions around marine plastic litter is complicated because many different types of plastic exist in the marine environment. Plastic size can range from microplastics (smaller than $5 \mathrm{~mm}$ ) to large plastic pieces such as "ghost nets" (lost or discarded fishing nets). The former can be toxic through adsorption of pollutants onto plastics and ingested by marine life and the latter can entangle animals and endanger mariners. Microplastics can originate from pellets or "nurdles" used in manufacturing, microbeads originate from certain cosmetic and personal care products, and textile fibres that enter the ocean in wastewater (primary microplastics) and from fragmentation of larger plastic pieces (secondary microplastics). According to Filella (2015) it is likely that this secondary source of microplastics dominates, or will dominate, the microplastics found in the marine environment. They base this expectation on the observation that the amount of macroplastic accumulating in the marine environment is increasing, while primary microplastics are predicted to decrease due to recent antipollution measurements. Therefore, by studying macroplastics in the ocean, one of the major and increasingly more important sources of microplastics are also studied. Unlike microplastics, larger plastics located using remote sensing could potentially be removed from the sea

\footnotetext{
* Corresponding author at: Environmental Research Institute, CfEE Building, UHI-NHC, Ormlie Road, Thurso KW14 7EE, Scotland, United Kingdom.

E-mail address: Lonneke.Goddijn-Murphy@uhi.ac.uk (L. Goddijn-Murphy).
} 
and coastlines - contributing to the effort to "clean up" the ocean (Sherman and van Sebille, 2016). Plastic comes in many different chemical compositions, each with different properties and buoyancy. Common marine plastic polymers include polyethylene (PE), polypropylene (PP), polyvinylchloride (PVC), polystyrene (PS), and polyamide (nylons), while they may be in the form of pellets, beads, films, fragments, fibres/filaments, and foamed plastic. Marine plastic litter persists in the environment for varying, and mostly very long, times; it degrades under the influence of ultraviolet light of the sun and chemicals dissolved in seawater and fragments in breaking waves and collisions. The contribution of micro-organisms to the degradation of plastics in the marine environment by biological decomposition is negligible (Andrady, 2015). However, according to Eriksen et al. (2014), bacterial degradation becomes more important as plastic particles become smaller and facilitate their export from the sea surface in addition to the ingestion of smaller plastic particles by organisms. Plastic objects in the ocean attract marine life and all floating objects are biofouled. Biofouling will reduce the buoyancy of plastic particles, so that they sink below the sea surface. Small plastic items start sinking sooner than larger plastic items because buoyancy is related to item volume, whereas fouling is related to surface area, and small items have high surface area to volume ratios (Ryan, 2015). In summary, there is a wide range of sizes, types, shapes, and of chemical composition of plastic in the ocean. We will focus on floating macroplastics because buoyant microplastics do not stay on top of the ocean surface but are mostly in suspension and lost from the sea surface (Eriksen et al., 2014). Microplastics will therefore not be "seen" by our proposed method. Considering that marine plastic RS is still in its early stages, we think this is a reasonable starting point.

This paper is organized as in the following. First, we briefly describe the much-studied reflectance of sunlight of the open sea. Next, we investigate the consequences of introducing floating plastic to the sea surface in a theoretical approach and propose a mathematical reflectance model to calculate the changed reflectance. This model will necessarily be an approximation and in the consequent section, we discuss the neglected terms. Finally, we suggest measurements to verify the proposed model and give a short conclusion. The parameter definitions used in this paper are listed in Table 1 and illustrated in Figs. 1-2.

\section{Reflectance model}

\subsection{Light reflectance of natural waters}

As can be seen in Fig. 1a, downwelling sunlight hitting the water partly reflects directly at the water surface and partly penetrates the surface refracting downwards. In the water body, light photons are absorbed and scattered in all directions. Because of the repeated scattering, subsurface upwelling light in water is generally considered to be Lambertian, i.e., light is evenly distributed in all directions. If the water is optically deep (bottom is invisible), the fraction of light that scatters back upwards and passes through the water-air interface contains information about the optically active water constituents. The sub surface irradiance reflectance is generally found to be proportional to $b_{\mathrm{b}} /$ $\left(b_{\mathrm{b}}+a\right)$ (Gordon et al., 1975) or $b_{\mathrm{b}} / a$ (Morel and Prieur, 1977; Kirk, 1994) with $b_{\mathrm{b}}$ total backscattering coefficient and $a$ total absorption coefficient $\left(b_{\mathrm{b}}\right.$ and $a$ are dependent on the wavelength of light, $\left.\lambda\right)$. The main backscattering components are suspended sediments and phytoplankton (scattering by water molecules is negligible in comparison). Absorbing components are suspended sediments, phytoplankton, dissolved organic matter, and water itself. The optically active components determine the apparent colour of the water and their concentrations can be estimated from spectral reflectance measurements.

Downwelling sunlight consists of direct sunlight (the solar beam) and diffuse sky light (scattered in all directions); the composition of direct and diffuse light depends on the solar elevation angle and sky
Table 1

Definitions of the variables used in this paper; subscript " 0 " indicates in the absence of plastic.

\begin{tabular}{|c|c|c|}
\hline Variable & Definition & Unit \\
\hline$A_{\mathrm{p}}$ & Area covered by plastic, projected in nadir view & {$\left[\mathrm{m}^{2}\right]$} \\
\hline$A_{\mathrm{w}}$ & Total area projected in nadir view & {$\left[\mathrm{m}^{2}\right]$} \\
\hline$\varepsilon$ & $L_{\mathrm{ds}} / L_{\mathrm{ds}, 0}$ & \\
\hline$f$ & Plastic area fraction $A_{\mathrm{p}} / A_{\mathrm{t}}$ & \\
\hline$F$ & Fraction diffuse sky light $E_{\mathrm{d}, \mathrm{dif}} / E_{\mathrm{d}}$ & \\
\hline$E_{\mathrm{d}}$ & Downwelling irradiance in air & {$\left[\mathrm{wm}^{-2}\right]$} \\
\hline$E_{\mathrm{ws}}$ & Upwelling irradiance in water & {$\left[\mathrm{wm}^{-2}\right]$} \\
\hline$\lambda$ & Wavelength of light & {$[\mathrm{nm}]$} \\
\hline$L_{\mathrm{d}}$ & Downwelling radiance in air & {$\left[\mathrm{wm}^{-2} \mathrm{sr}^{-1}\right]$} \\
\hline$L_{\mathrm{ds}}$ & Downwelling radiance in water & {$\left[\mathrm{wm}^{-2} \mathrm{sr}^{-1}\right]$} \\
\hline$L_{\mathrm{p}}$ & Total plastic leaving radiance in air $\left(L_{\mathrm{pr}}+L_{\mathrm{pt}}\right)^{\mathrm{a}}$ & {$\left[\mathrm{wm}^{-2} \mathrm{sr}^{-1}\right]$} \\
\hline$L_{\mathrm{pr}}$ & $L_{\mathrm{d}}$ reflected by plastic in air $^{\mathrm{a}}$ & {$\left[\mathrm{wm}^{-2} \mathrm{sr}^{-1}\right]$} \\
\hline$L_{\mathrm{ps}}$ & Total plastic leaving, downwelling radiance in water & {$\left[\mathrm{wm}^{-2} \mathrm{sr}^{-1}\right]$} \\
\hline$L_{\mathrm{pt}}$ & $L_{\mathrm{ws}}$ transmitted upwards through plastic in air $^{\mathrm{a}}$ & {$\left[\mathrm{wm}^{-2} \mathrm{sr}^{-1}\right]$} \\
\hline$L_{\mathrm{w}}$ & Total water leaving radiance in air $\left(L_{w r}+L_{\mathrm{wt}}\right)^{\mathrm{a}}$ & {$\left[\mathrm{wm}^{-2} \mathrm{sr}^{-1}\right]$} \\
\hline$L_{\mathrm{wr}}$ & $L_{\mathrm{d}}$ reflected by air-water interface ${ }^{\mathrm{a}}$ & {$\left[\mathrm{wm}^{-2} \mathrm{sr}^{-1}\right]$} \\
\hline$L_{\mathrm{ws}}$ & Sub surface upwelling radiance in water ${ }^{\mathrm{a}}$ & {$\left[\mathrm{wm}^{-2} \mathrm{sr}^{-1}\right]$} \\
\hline$L_{\mathrm{wt}}$ & $L_{\mathrm{ws}}$ transmitted through water-air interface ${ }^{\mathrm{a}}$ & {$\left[\mathrm{wm}^{-2} \mathrm{sr}^{-1}\right]$} \\
\hline$L_{\mathrm{t}}$ & Total upwelling radiance $\left(L_{w}+L_{\mathrm{p}}\right)^{\mathrm{a}}$ & {$\left[\mathrm{wm}^{-2} \mathrm{sr}^{-1}\right]$} \\
\hline$R$ & Ratio of upwelling radiance in nadir view and $E_{\mathrm{d}}$ in air & {$\left[\mathrm{sr}^{-1}\right]$} \\
\hline$R_{\mathrm{p}}$ & $L_{\mathrm{p}} / E_{\mathrm{d}}$ & {$\left[\mathrm{sr}^{-1}\right]$} \\
\hline$R_{\mathrm{t}}$ & $L_{\mathrm{t}} / E_{\mathrm{d}}$ & {$\left[\mathrm{sr}^{-1}\right]$} \\
\hline$R_{\mathrm{w}}$ & $L_{\mathrm{w}} / E_{\mathrm{d}}$ & {$\left[\mathrm{sr}^{-1}\right]$} \\
\hline$\rho_{\mathrm{p}}$ & $L_{\mathrm{pr}} / L_{\mathrm{d}}$ & \\
\hline$\rho_{\mathrm{p}, \mathrm{RS}}$ & $L_{\mathrm{pr}} / \mathrm{E}_{\mathrm{d}}$ & {$\left[\mathrm{sr}^{-1}\right]$} \\
\hline$\rho_{\mathrm{pw}}$ & Fraction of $L_{\mathrm{ws}}$ reflected by plastic & \\
\hline$\rho_{w}$ & $L_{\mathrm{wr}} / L_{\mathrm{d}}$ & \\
\hline$\rho_{\mathrm{w}, \mathrm{RS}}$ & $L_{w r} / E_{\mathrm{d}}$ & {$\left[\mathrm{sr}^{-1}\right]$} \\
\hline$r_{\mathrm{ws}}$ & $L_{\mathrm{ws}} / L_{\mathrm{ds}}$ & \\
\hline$\tau_{\mathrm{p}}$ & $L_{\mathrm{pt}} / L_{\mathrm{ws}}$ & \\
\hline$\tau_{\mathrm{pw}}$ & Fraction of $L_{\mathrm{d}}$ transmitted through plastic & \\
\hline$\tau_{\mathrm{w}}$ & $L_{\mathrm{ds}, 0} / L_{\mathrm{d}}$ & \\
\hline
\end{tabular}

${ }^{\text {a }}$ In nadir view.

conditions (Jerlov, 1968). Direct and diffuse skylight interact differently with the water body.

\subsection{Light reflectance of water littered with floating plastic}

Plastic objects floating on the water surface control surface leaving light in a number of ways, (1) downwelling light reflects differently off plastic than off water, (2) transmittance of downwelling light through plastic is different from transmittance through the air-water interface, changing the underwater light climate and hence the back scattered upwelling light, and (3) subsurface upwelling light transmits through plastic differently than through the water-air interface. The different pathways, illustrated in Fig. 1b, explain why measuring marine plastic is different from retrieving concentrations of optically active water components through their spectral scattering and absorption properties (Section 2.1). The mathematical model will have to include radiative transfer in water itself, as well as light interaction with plastics on the water surface with different optical properties (e.g., colour, transparency, and shape). We propose a mathematical model that can help select optimal wavelengths, design experiments, and develop a working algorithm for remote sensing marine plastic.

With $A_{\mathrm{t}}$ the total water surface area- and $A_{\mathrm{p}}$ the plastic covered area projected in nadir view (Fig. 2), the plastic area fraction, $f$, is defined by $A_{\mathrm{p}} / A_{\mathrm{t}}$. Both plastic- and open water leaving radiance, $L_{\mathrm{p}}$ and $L_{\mathrm{w}}$ [Wm ${ }^{-2} \mathrm{sr}^{-1}$ ], contribute to total above surface upwelling radiance, $L_{\mathrm{t}}$, leaving this area in nadir view. $L_{\mathrm{t}}$ received by the sensor in nadir view can be estimated with Eq. (1),

$L_{t}(\lambda)=(1-f) L_{w}(\lambda)+f L_{p}(\lambda)$

For (semi-)transparent plastic, $L_{\mathrm{p}}$ does not only represent plastic reflected sunlight in air, as subsurface upwelling light that is 

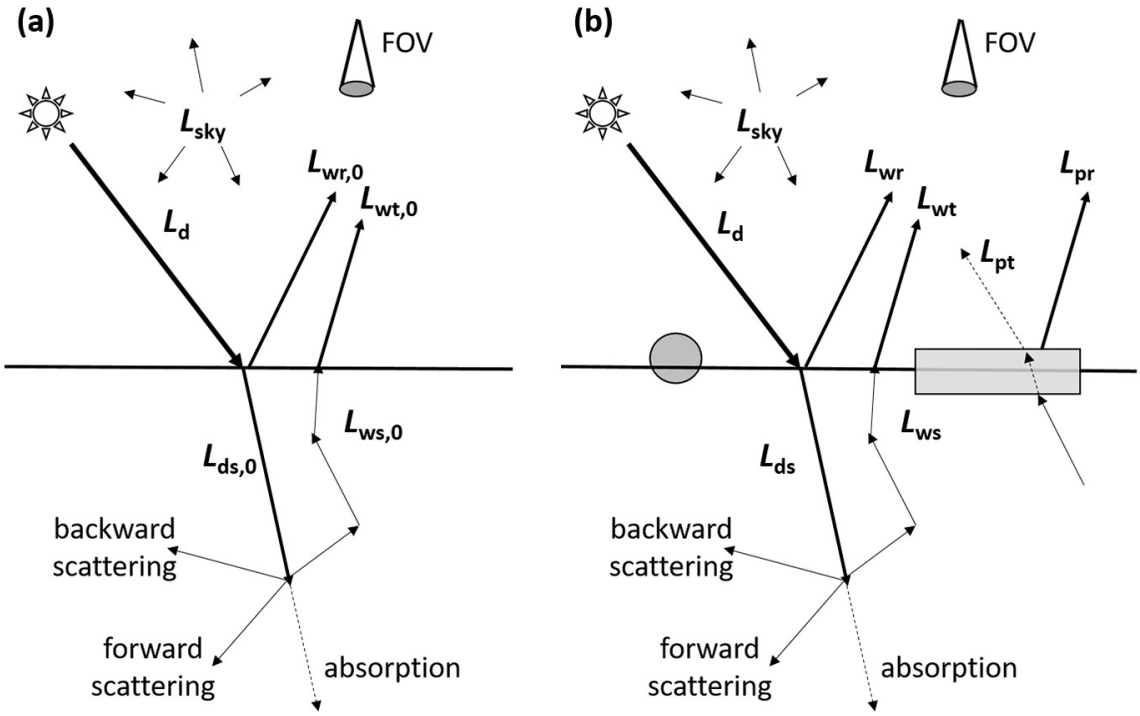

Fig. 1. Schematic of sunlight hitting (a) an open water body, and (b) the same water body but with floating plastic. With $\mathrm{L}_{\mathrm{d}}$ total downwelling sunlight (solar beam + diffuse sky light), $\mathrm{L}_{\mathrm{ds}}$ subsurface downwelling light, $\mathrm{L}_{\mathrm{ws}}$ subsurface upwelling light, $\mathrm{L}_{\mathrm{wr}}$ light reflected directly off the water surface, $\mathrm{L}_{\mathrm{wt}}$ subsurface upwelling light transmitted through the water-air interface, $\mathrm{L}_{\mathrm{p}}$ light reflected off the plastic and $\mathrm{L}_{\mathrm{pt}}$ subsurface upwelling light transmitted through the plastic. $\mathrm{L}_{\mathrm{w}}$ is total water leaving light, $\mathrm{L}_{\mathrm{wr}}+\mathrm{L}_{\mathrm{wt}}$, and $\mathrm{L}_{\mathrm{p}}$ is total plastic leaving light, $\mathrm{L}_{\mathrm{pt}}+\mathrm{L}_{\mathrm{pr}}$; subscript ' 0 ' indicates the variables in the absence of plastic and FOV is field of view.

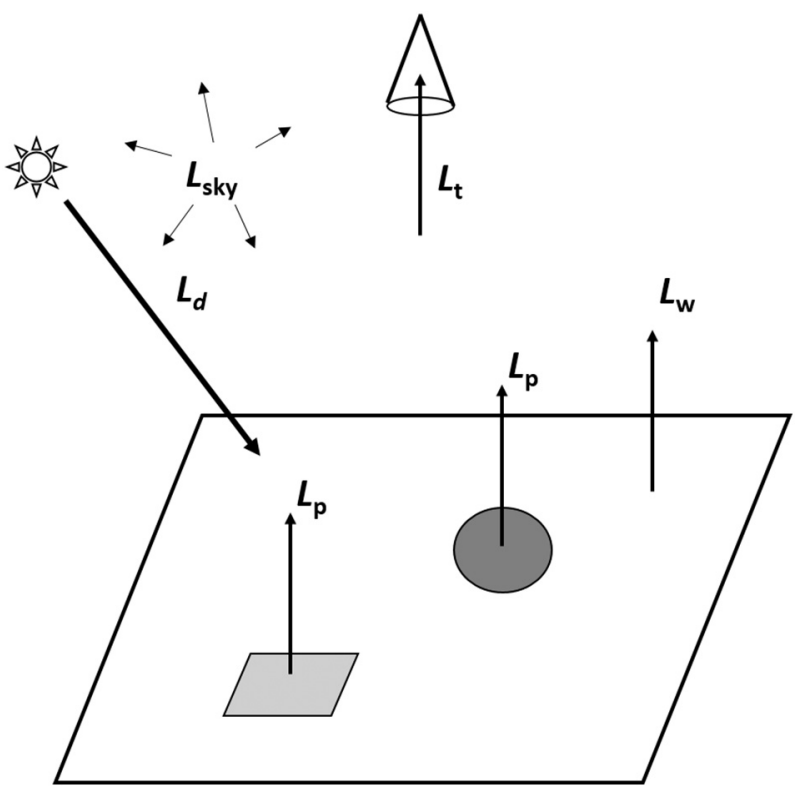

Fig. 2. As Fig. 1 but seen from above, with $A_{t}\left(A_{p}\right)$ total (total plastic) surface area in the frame projected in nadir view, with $\rho_{\mathrm{p}}$ and $\tau_{\mathrm{p}}\left(\mathrm{L}_{\mathrm{pr}} / \mathrm{L}_{\mathrm{d}}\right.$ and $\mathrm{L}_{\mathrm{pt}} / \mathrm{L}_{\mathrm{ws}}$ respectively as in Fig. 1b) representing the total spectral radiance reflectance and transmittance of the plastic. The coefficients $\rho_{\mathrm{p}}$ and $\tau_{\mathrm{p}}$ are dependent on light conditions, i.e., the solar elevation angle in the field and the fraction diffuse sky light. Eqs. (1) and (2) lead to an estimation of $f$ from remote sensing.

transmitted through the plastic also contributes to $L_{\mathrm{p}}$ :

$L_{\mathrm{p}}=\rho_{\mathrm{p}} L_{\mathrm{d}}+\tau_{\mathrm{p}} L_{\mathrm{ws}}$

Radiance reflectance, $\rho_{\mathrm{p}}$, is defined as $L_{\mathrm{pr}} / L_{\mathrm{d}}$ and transmittance $\tau_{\mathrm{p}}$ as $L_{\mathrm{pt}} / L_{\mathrm{ws}}$. For a flat horizontal surface of one single layer of plastic, $\rho_{\mathrm{p}}$, equals the Fresnel reflectance for normal incident light. In reality $L_{\mathrm{p}}$ is determined by the object's shape, solidness and surface roughness (through $\rho_{\mathrm{p}}$ ) in combination with the angle of incident light that is reflected in nadir view $\left(L_{\mathrm{d}}\right)$ since the angular distribution of $L_{\mathrm{d}}$ is not uniform. Downwelling sunlight consists of the solar beam and diffuse sky light, whose proportions depend on sky conditions (e.g., cloudy, clear or hazy), solar elevation angle and wavelength (Jerlov, 1968). Normal incident light can be regarded as diffuse as the sun is normally not at zenith angle. We discuss these bi-directional effects and other approximations later in Section 3.

Subsurface upwelling light, $L_{\mathrm{ws}}$, that is not reflected at the water- plastic interface is transmitted through the plastic object where light may be lost due to absorption and internal reflection. We define $\tau_{\mathrm{p}}$ as the fraction of subsurface upwelling light hitting the plastic object that was not lost. Eqs. (1) and (2) lead to an estimation of $f$

$f(\lambda)=\frac{L_{\mathrm{t}}(\lambda)-L_{\mathrm{w}}(\lambda)}{L_{\mathrm{p}}(\lambda)-L_{\mathrm{w}}(\lambda)}=\frac{L_{\mathrm{t}}(\lambda)-L_{\mathrm{w}}(\lambda)}{\rho_{\mathrm{p}}(\lambda) L_{\mathrm{d}}(\lambda)+\tau_{\mathrm{p}}(\lambda) L_{\mathrm{ws}}(\lambda)-L_{\mathrm{w}}(\lambda)}$

$L_{\mathrm{ws}}$ in water is estimated from $L_{\mathrm{w}}$ in air by accounting for the loss caused by internal reflection, $\rho_{0}$, at the water-air interface and the effect of the radiant flux being confined to a wider solid angle of light as it passes across the water-air interface. According to Austin (1980), radiance increases with a factor 1.84 as it transfers from air to seawater. $L_{\mathrm{w}}$ is the sum of water surface reflected sunlight, $L_{\mathrm{wr}}$, and subsurface upwelling light transmitted through the water surface, $L_{\mathrm{wt}}$ (Fig. 1); knowing this, we can write $L_{\mathrm{ws}}$ in above surface terms,

$L_{\mathrm{ws}}=1.84 L_{\mathrm{wt}}=1.84\left(L_{\mathrm{w}}-\rho_{\mathrm{w}} L_{\mathrm{d}}\right)$

with $\rho_{\mathrm{w}}$ the direct reflectance of seawater from air to seawater similar to the Fresnel reflectance of seawater for $0^{\circ}$ angle of incidence (Hobson and Williams, 1971). In pure water the wavelength dependence of $\rho_{\mathrm{w}}$ is negligible for wavelengths between 400 and $2000 \mathrm{~nm}$ with refractive index decreasing from 1.343 to 1.304 (Irvine and Pollack, 1968). Thus $2.1 \%$ to $1.7 \%$ of the light incident normally on the air-water interface will be reflected back at these wavelengths (Hecht and Zajac, 1974).

Using Eq. (4), we can express Eq. (3) solely in terms of radiance measurements in air,

$f(\lambda)=\frac{L_{\mathrm{t}}(\lambda)-L_{\mathrm{w}}(\lambda)}{\rho_{\mathrm{p}}(\lambda) L_{\mathrm{d}}(\lambda)+\tau_{\mathrm{p}}(\lambda) 1.84\left[L_{\mathrm{w}}(\lambda)-\rho_{\mathrm{w}} L_{\mathrm{d}}(\lambda)\right]-L_{\mathrm{w}}(\lambda)}$

A common definition of reflectance in remote sensing is the ratio of upwelling light, $L$, and total downwelling irradiance, $E_{\mathrm{d}}\left[\mathrm{Wm}^{-2}\right]$,

$R(\lambda)=L(\lambda) / E_{\mathrm{d}}(\lambda)\left[\mathrm{sr}^{-1}\right]$

We compute $R$ for nadir-viewing directions but in actual airborne or satellite remote sensing the sensor usually observes in an off-nadir direction. The correction for this is beyond the scope of this paper. Using $R_{\mathrm{i}}$ with subscript " $i$ " relating to $L_{\mathrm{i}}$ (Table 1$), \rho_{\mathrm{p}, \mathrm{RS}}=L_{\mathrm{pr}} / E_{\mathrm{d}}$ and $\rho_{\mathrm{w}, \mathrm{RS}}=L_{\mathrm{wr}} / E_{\mathrm{d}}$, Eqs. (3) \& (5) can be written as

$f(\lambda)=\frac{R_{\mathrm{t}}(\lambda)-R_{\mathrm{w}}(\lambda)}{R_{\mathrm{p}}(\lambda)-R_{\mathrm{w}}(\lambda)}=\frac{R_{\mathrm{t}}(\lambda)-R_{\mathrm{w}}(\lambda)}{\rho_{\mathrm{p}, \mathrm{RS}}(\lambda)+\tau_{\mathrm{p}}(\lambda) 1.84\left(R_{\mathrm{w}}(\lambda)-\rho_{\mathrm{w}, \mathrm{RS}}\right)-R_{\mathrm{w}}(\lambda)}$

Eq. (7) shows how the plastic fraction can be estimated from RS measurements in air if $\rho_{\mathrm{p}, \mathrm{RS}}, \tau_{\mathrm{p}}$ and $\rho_{\mathrm{w}, \mathrm{RS}}$ are known. $L_{\mathrm{w}}$, and hence $R_{\mathrm{w}}$, 
is not strictly the same in open waters as in plastic littered waters because the presence of floating plastic can affect underwater light climate through shading and filtering. Therefore, using $R_{\mathrm{w}, 0}$ to estimate $R_{\mathrm{W}}$ is an approximation:

$f(\lambda)=\frac{R_{\mathrm{t}}(\lambda)-R_{\mathrm{w}, 0}(\lambda)}{\rho_{\mathrm{p}, \mathrm{RS}}(\lambda)+\tau_{\mathrm{p}}(\lambda) 1.84\left(R_{\mathrm{w}, 0}(\lambda)-\rho_{\mathrm{w}, \mathrm{RS}}\right)-R_{\mathrm{w}, 0}(\lambda)}$

In the next section (Section 3.3) we evaluate this approximation. This single band algorithm is expected to work best for wavelengths where $R_{\mathrm{w}, 0}$ is near zero but where $R_{\mathrm{p}}$ is high, for example a wavelength of $750 \mathrm{~nm}$ (spectra from Asner, 2016). When using larger wavelengths in the SWIR, note that pure water has absorption peaks near $1.45 \mu \mathrm{m}$, $1.94 \mu \mathrm{m}$ and $2.95 \mu \mathrm{m}$ (Irvine and Pollack, 1968). Absorption at the latter wavelength is $11.7 \times 10^{-6} \mathrm{~m}^{-1}$, indicating that a thin film of water on the plastic can significantly reduce plastic leaving light.

The inverse of the derivative of Eq. (8) with respect to $R_{\mathrm{t}}$ computes the sensitivity of $R_{\mathrm{t}}$ to changes in $f$,

$d R_{\mathrm{t}}(\lambda) / d f=\rho_{\mathrm{p}, \mathrm{RS}}(\lambda)+\tau_{\mathrm{p}}(\lambda) 1.84\left(R_{\mathrm{w}, 0}(\lambda)-\rho_{\mathrm{w}, \mathrm{RS}}\right)-R_{\mathrm{w}, 0}(\lambda)$

We calculated $\mathrm{d} R_{\mathrm{t}}(850) / \mathrm{d} f$ for a single solid flat layer of plastic so that $L_{\mathrm{d}}$ represents light of normal incidence for light reflected in nadir view. $L_{\mathrm{d}}$ is composed of diffuse sky light if the sun is not in zenith, and if we that assume that sky radiance is completely diffuse, downwelling diffuse irradiance, $E_{\mathrm{d}, \mathrm{dif}}$, equals $\pi L_{\mathrm{d}}$ (Jerlov, 1968). Dekker (1990) measured diffuse irradiance fractions, $F$ defined by $E_{\mathrm{d}, \mathrm{dif}} / E_{\mathrm{d}}$, under various cloudless sky conditions. $F$ decreases with increasing wavelength, and for $850 \mathrm{~nm}$ wavelength he found $F$ to be $0.07(0.23)$ for a clear (hazy) sky. Using this, $E_{\mathrm{d}}=E_{\mathrm{d} \text {,dif }} / F$, so that $\rho_{\mathrm{p}, \mathrm{RS}}=\rho_{\mathrm{p}} /(\pi / F)$ and $\rho_{\mathrm{w}, \mathrm{RS}}=0.02 /(\pi / F)$. Plastic reflectance in nadir direction, and hence $\mathrm{d} R_{\mathrm{t}} / \mathrm{d} f$, therefore increases with increasing fraction of diffuse sky light. In the NIR, subsurface RS reflectance is $<1 \%$ for wavelengths for most natural water types but higher for turbid waters where it is $1-2 \%$ (Moore et al., 2014). The term $\left(R_{\mathrm{w}, 0}-\rho_{\mathrm{w}, \mathrm{RS}}\right)$ in Eqs. (7)-(9) is therefore dominated by $R_{\mathrm{w}, 0}$. We evaluated Eq. (9) for $\rho_{\mathrm{p}}$ and $\tau_{\mathrm{p}}$ ranging from 0 to 1 ; for light hitting the plastic at zero incidence, transmittance of upwelling light is the same as for downwelling light and $\rho_{\mathrm{p}}+\tau_{\mathrm{p}}+\alpha_{\mathrm{p}}=1$, with $\alpha_{\mathrm{p}}$ the light absorbed in the plastic. We repeated this for subsurface RS reflectance of $0.005,0.01,0.02$ and 0.035 , corresponding with $R_{\mathrm{w}, 0}$, levels of $0.003,0.005,0.01,0.02$ respectively according to the standard NASA conversion from above-water to belowwater (Moore et al., 2014). We did this for $F$ of 0.07 and of 0.23 to examine the effect of lighting conditions. The results (Fig. 3) confirm that the RS signal is expected to increase with decreasing $R_{\mathrm{w}, 0}$ and with increasing $F$. If $R_{\mathrm{w}, 0}$ is small, the signal is controlled by plastic reflectance and increasing with increasing $\rho_{\mathrm{p}}$. This can be explained as for increasing $R_{\mathrm{w}, 0}$, reflectance is no longer uniquely important, with the signal increasing/decreasing with increasing transparency/absorption.

For high $R_{\mathrm{w}, 0}, \mathrm{~d} R_{\mathrm{t}} / \mathrm{d} f$ can become zero and then negative indicating that the RS signal reduces with increasing plastic fraction. Eq. (8) will therefore perform better in clearer waters.

\subsubsection{Dual band algorithm}

Effects of the varying background colour of natural water should be taken into account and a possibility is measuring spectral reflectance at more than one wavelength to separate the plastic- from the water signal. If we can find a second wavelength for which $R_{\mathrm{w}}\left(\lambda_{1}\right) \approx R_{\mathrm{w}}\left(\lambda_{2}\right)$ and $R_{\mathrm{p}}\left(\lambda_{1}\right) \neq R_{\mathrm{p}}\left(\lambda_{2}\right)$ then we can estimate $f$ with:

$f\left(\lambda_{1}, \lambda_{2}\right)=\frac{R_{\mathrm{t}}\left(\lambda_{1}\right)-R_{\mathrm{t}}\left(\lambda_{2}\right)}{R_{\mathrm{p}}\left(\lambda_{1}\right)-R_{\mathrm{p}}\left(\lambda_{2}\right)}$

$$
\begin{aligned}
& f\left(\lambda_{1}, \lambda_{2}\right) \\
& \quad=\frac{R_{\mathrm{t}}\left(\lambda_{1}\right)-R_{\mathrm{t}}\left(\lambda_{2}\right)}{\rho_{\mathrm{p}, \mathrm{RS}}\left(\lambda_{1}\right)-\rho_{\mathrm{p}, \mathrm{RS}}\left(\lambda_{2}\right)+1.84\left(\tau_{\mathrm{p}}\left(\lambda_{1}\right)-\tau_{\mathrm{p}}\left(\lambda_{2}\right)\right)\left(R_{\mathrm{w}}\left(\lambda_{1}\right)-\rho_{\mathrm{w}, \mathrm{RS}}\left(\lambda_{1}\right)\right)}
\end{aligned}
$$

A possibility could be a $\lambda_{1}$ in the VIS-NIR and a second higher wavelength, $\lambda_{2}$, in the SWIR (spectra from Asner, 2016).

\section{Discussion}

\subsection{Approximations}

For the derivation of our model, a number of approximations were necessary. First, the proposed reflectance model is for one type of plastic in two dimensions, i.e., a single smooth flat layer with specific physical and optical properties, while in reality marine plastic litter consists of all kinds of shapes and chemical compositions. In truth, a plastic litter object is three dimensional and could reflect light back in the sensor's view from its sides, especially when it is pitching and rolling on the ocean waves. Also, if three dimensional shapes change the lighting environment near the sea surface, they can affect each other's light reflectance. In these cases, the plastic reflectance coeffcient is also dependent on plastic concentration and $\rho_{\mathrm{p}, \mathrm{RS}}(\lambda)=\rho_{\mathrm{p}, \mathrm{RS}}(\lambda, f)$. A plastic surface is usually not just a specular reflector as illustrated in Fig. 1b (smooth surface), but can reflect light in more than one direction as well (rough surface). The latter is known as diffuse reflection and enhances $\rho_{\mathrm{p}, \mathrm{RS}}$ because not only sky light is scattered in nadir view, the solar beam is as well. (The enhancement is comparable to the one by the fraction diffuse sky light as described in Section 2.2). To complicate things further, if the plastic surface is wet, water can fill in the gaps and smooth out the surface thereby reducing diffuse reflectance. In addition, water absorbs strongly in at wavelengths in the infrared and a thin layer of water can reduce the signal further at these wavelengths.

A next step will be to investigate further how dissimilar the different plastics interact with light at the wavelengths of interest and how their signals can be 'mixed'. For a mix of a number of $m$ plastic litter types ' $i$ ' in the water, each with $\rho_{\mathrm{p}, \mathrm{RS}, \mathrm{i}}(\lambda)$ and fraction $f_{\mathrm{i}}$ (total $f=\Sigma f_{\mathrm{i}}$ ), a first approximation of their combined signal could be

$R_{t}(\lambda)=R_{w, 0}(\lambda)+\sum_{i=1}^{m} f_{i} \rho_{p, R S, i}\left(\lambda, f_{1}, \ldots, f_{m}\right)-R_{w, 0}(\lambda)$

The challenge of Eq. (11) is, is to invert it and derive $f_{\mathrm{i}}$ and total $f$ from $R_{\mathrm{t}}$; in theory we could apply different wavelengths, selected from the plastic reflectance spectra, to reveal different plastic fractions. The idea is that by selecting the wavelength of an absorption band of a plastic type, this plastic would be excluded from the signal.

Marine plastic litter that has spent some time in the ocean usually does not have a clean surface but is fouled by a variety of marine life. Organisms such as barnacles or seaweeds growing on the plastic can sink a plastic object below the water surface, hiding it from view. A biofilm of algae reduces reflectance of visible light by light absorption (Dobretsov et al., 2014). Different species of algae contain different pigments with unique absorption bands, but all algae contain chlorophyll which absorbs around 672-680 $\mathrm{nm}$. All macro- and microalgae have low reflectance in the visible and high reflectance in the NIR. For our RS algorithm we should therefore select wavelength(s) in the infrared rather than in the visible spectrum. How biofilms affect the optical properties of the plastic they inhabit should be a subject of future study, using marine plastic litter collected at sea or on the beach.

In theory our method of geometrical optics applies to objects whose dimensions are larger than a couple of radiance wavelengths (in the order of micrometres in the VIS-SWIR spectrum) and would therefore include microplastics but particles this small are quickly removed from the ocean surface (Eriksen et al., 2014). For particles small in comparison to the wavelength, light scattering is known as Rayleigh scattering (Hecht and Zajac, 1974). Because we only consider surface plastic, studies of the composition of marine plastic and their vertical profiles are necessary to get a full picture of marine plastic pollution. Plastic pollution can be problem in freshwater as well (Driedger et al., 2015) and our suggested RS algorithm could apply here too but it will 

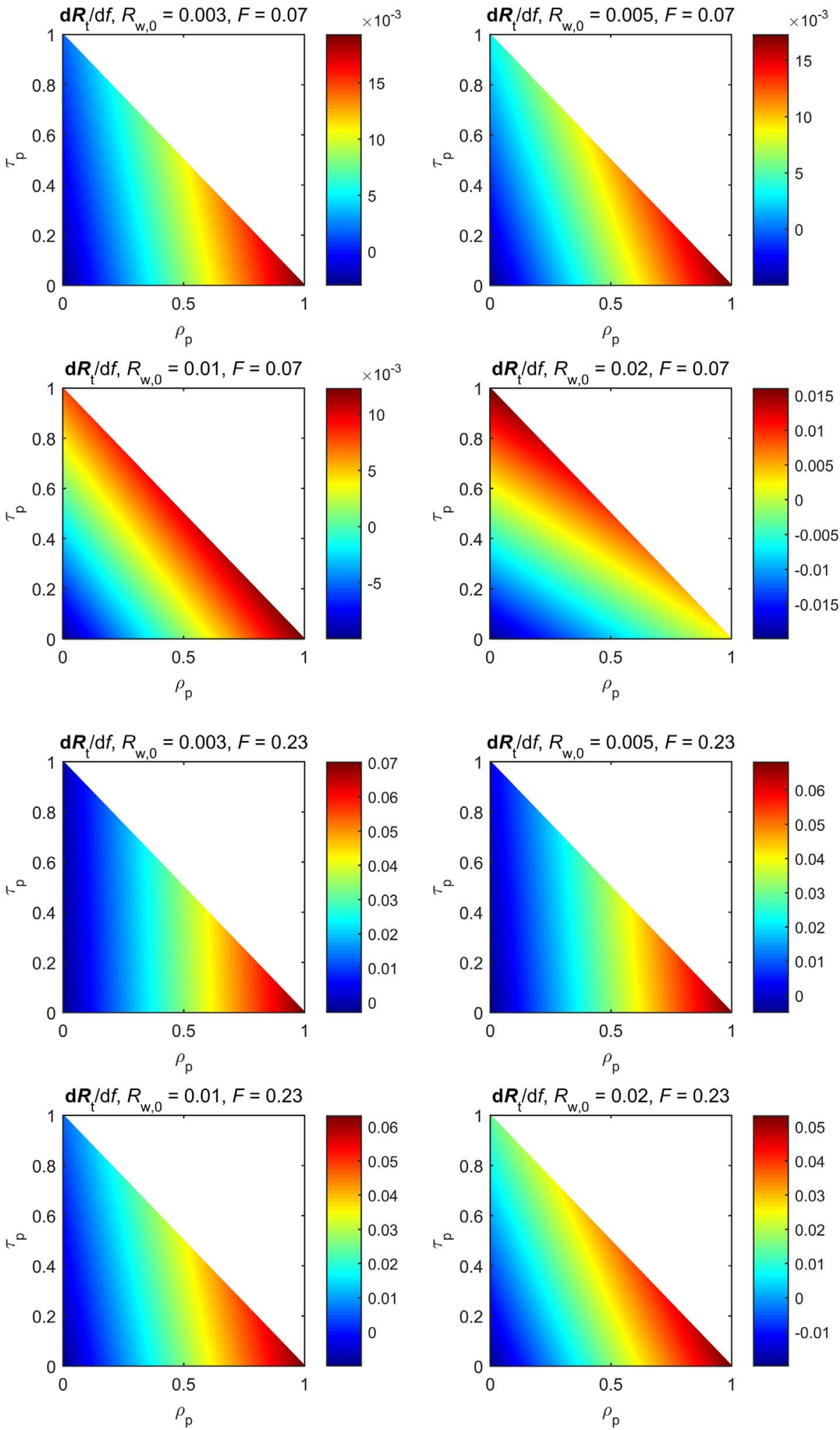

Fig. 3. Computations of $d_{R_{t}} / d f$ (Eq. (9)) for a flat, single layer piece of plastic with a range of reflectance and transmittance coefficients using $\mathrm{F}$ at $850 \mathrm{~nm}$ wavelength for (top) clear sky $(\mathrm{F}=0.07)$, and (bottom) hazy sky $\left(F=0.23\right.$ ). For $R_{w, 0}=0.003,0.005,0.01$, and 0.02 (corresponding with respective sub surface RS reflectance of $0.005,0.01,0.02$ and 0.035 ), for clear to turbid natural waters (Moore et al., 2014). not work as well in turbid waters due to the higher subsurface reflectance in the NIR (Moore et al., 2014). Also freshwaters are more likely to have emerging vegetation interfering with the RS signal. Oceans are generally clearer than coastal and inland water, and we expect our model to perform better in the open ocean. Other approximations are the bi-directionality of the plastic reflectance of sunlight and the shading and filtering of downwelling light by plastic on the water surface. These issues will be discussed in the following.

\subsection{Bidirectional reflectance of marine plastic litter}

RS algorithms linking a water body's inherent optical properties to reflectance values are based on subsurface irradiance reflectance or reflectance defined by the ratio of subsurface upwelling radiance and above surface downwelling irradiance. The water body below the surface is sometimes treated as a Lambertian reflector (reflected light is completely diffuse and unpolarised so that $E_{\mathrm{ws}} / L_{\mathrm{ws}}=\pi$, (Jerlov, 1968) 
independent on the angle of incidence. This assumption cannot be made for plastic objects as the reflectance of plastic objects, $\rho_{\mathrm{p}}$, is dependent on the angle of the light of incidence. We assumed $0^{\circ}$ angle of incident radiance, $\theta_{\mathrm{i}}$, (Section 2.2), which corresponds with a flat plastic surface at right angles with incoming radiance. In reality, plastic litter can have many shapes with surfaces at different angles, and downwelling radiance at different angles is reflected in nadir direction $\left.L_{\mathrm{pr}}=L_{\mathrm{d}}\left(\theta_{\mathrm{i}}\right) \rho_{\mathrm{p}}\left(\theta_{\mathrm{i}}\right)\right)$. However, marine plastics floating on the sea surface pitch and roll on the waves, producing more equally distributed reflected light. In addition, downwelling light is not completely diffuse so that $\rho_{\mathrm{p}, \mathrm{RS}}$ is also dependent on the angular distribution of downwelling light $\left(\rho_{\mathrm{p}, \mathrm{RS}}=\rho_{\mathrm{p}}\left(\theta_{\mathrm{i}}\right) L_{\mathrm{d}}\left(\theta_{\mathrm{i}}\right) / E_{\mathrm{d}}\right)$. The angular distribution depends on the composition of sunlight of direct light and diffuse skylight, controlled by the solar elevation angle and sky conditions such as cloud cover (Jerlov, 1968). How this averages out depends on the integration time of the recorded light. If $A_{\mathrm{t}}$ is not small compared to the distance between the sea surface and the sensor, the position of $A_{\mathrm{p}}$ within can also modify the measured radiance, i.e., plastic objects in the centre will contribute more than those nearer the edge. As floating objects move around on the sea surface, this may also average out in practice.

\subsection{Shading and filtering of downwelling light by plastic}

Sub-surface upwelling radiance, $L_{\mathrm{ws}}$, changes in the presence of surface plastic because of changes in sub-surface downwelling radiance, $L_{\mathrm{ds}},\left(L_{\mathrm{ws}}=r_{\mathrm{ws}} L_{\mathrm{ds}}\right.$ and $\left.L_{\mathrm{ws}, 0}=r_{\mathrm{ws}} L_{\mathrm{ds}, 0}\right)$. However, subsurface radiance reflectance in the water body below the surface should be the same with and without plastic coverage $\left(r_{\mathrm{ws}}=L_{\mathrm{ws}, 0} / L_{\mathrm{ds}, 0}=L_{\mathrm{ws}} / L_{\mathrm{ds}}\right)$. Assume $L_{\mathrm{ds}}$ is a fraction of $L_{\mathrm{ds}, 0}$ by a spectral shading factor, $\varepsilon$, depending on how much plastic is covering the water surface $\left(L_{\mathrm{ds}}=\varepsilon(f, \lambda) L_{\mathrm{ds}, 0}\right.$, and hence $L_{\mathrm{ws}}=\varepsilon(f, \lambda) L_{\mathrm{ws}, 0}$, with $\varepsilon(f=0)=1$ and $\left.\varepsilon(f>0)<1\right)$. Using Eq. (4), $L_{\mathrm{w}, 0}=L_{\mathrm{ws}, 0} / 1.84+\rho_{\mathrm{w}} L_{\mathrm{d}}$ and $L_{\mathrm{w}}=L_{\mathrm{ws}} / 1.84+\rho_{\mathrm{w}} L_{\mathrm{d}}$, leads to

$L_{\mathrm{w}}=\varepsilon L_{\mathrm{w}, 0}+\rho_{\mathrm{w}}(1-\varepsilon) L_{\mathrm{d}} \quad \Rightarrow \quad R_{\mathrm{w}}=\varepsilon R_{\mathrm{w}, 0}+\rho_{\mathrm{w}, \mathrm{RS}}(1-\varepsilon)$

With Eq. (12) and $L_{\mathrm{ws}}=\varepsilon(f, \lambda) L_{\mathrm{ws}, 0}$, Eq. (7) can be rewritten in terms of in air measurements of total RS reflectance and RS reflectance of the open water surface,

$$
\begin{aligned}
f(\lambda)= & \frac{R_{\mathrm{t}}(\lambda)-\left[\varepsilon(f, \lambda) R_{\mathrm{w}, 0}(\lambda)+\rho_{\mathrm{w}, \mathrm{RS}}(1-\varepsilon(f, \lambda))\right]}{\rho_{\mathrm{p}, \mathrm{RS}}(\lambda)+\tau_{\mathrm{p}}(\lambda) \varepsilon(f, \lambda) 1.84\left(R_{\mathrm{w}, 0}(\lambda)-\rho_{\mathrm{w}, \mathrm{RS}}\right)} \\
& -\left[\varepsilon(f, \lambda) R_{\mathrm{w}, 0}(\lambda)+\rho_{\mathrm{w}, \mathrm{RS}}(1-\varepsilon(f, \lambda))\right]
\end{aligned}
$$

If we disregard change in the subsurface radiance caused by plastic floating at the surface, i.e., $\varepsilon \approx 1$, Eq. (13) reduces to Eq. (8). We can solve Eq. (13) with an iterative calculation using the relationship between $\varepsilon(f, \lambda)$ and $f$ (Eq. (A3)). In Appendix A a theoretical equation for the spectral shading factor is derived from the optical model.

\subsection{Future work}

\subsubsection{Field}

In the proposed field experiment, a range of plastic fractions of one similar, common type (e.g., plastic drink bottles or carrier bags) on a restricted area of sea surface is placed in the field of view (Fig. 2) and $L_{\mathrm{t}}$ and $E_{\mathrm{d}}$ are measured using a spectrometer in the VIS-SWIR spectrum. $L_{\mathrm{w}, 0}$, is measured using the same system but in the absence of plastic. By controlling the field of view of the radiometer, a sufficiently large and constant sea surface is measured. Thus values of $R_{\mathrm{w}, 0}(\lambda)$ and of $R_{\mathrm{t}}(\lambda)$ are measured as a function of $f$. A linear fit to Eq. (8) for $R_{\mathrm{w}, 0} \approx \rho_{\mathrm{w}, \mathrm{RS}}$, rewritten as Eq. (14), of the measurements can give $\rho_{\mathrm{p}, \mathrm{RS}}(\lambda)$ :

$R_{\mathrm{t}}(\lambda)=R_{\mathrm{w}, 0}(\lambda)+f\left(\rho_{\mathrm{p}, \mathrm{RS}}(\lambda)-R_{\mathrm{w}, 0}(\lambda)\right)$

If we consider the shading, Eq. (13) can be similarly rewritten, with $\rho_{\mathrm{w}, \mathrm{RS}} \approx 0$,

$R_{\mathrm{t}}(\lambda)=\varepsilon(f, \lambda) R_{\mathrm{w}, 0}(\lambda)+f\left(\rho_{p, R S}(\lambda)-\varepsilon(f, \lambda) R_{\mathrm{w}, 0}(\lambda)\right)$
The theoretical equation for $\varepsilon(f, \lambda)$ can be expressed as $\left(1-c_{1} f\right) /(1$ $c_{2} f$ ) (Eq. (A3)), so if we have enough measurements of $R_{\mathrm{t}}$ over a range of $f$ values we could find $c_{1}, c_{2}$ (and thus $\varepsilon$ ), and $\rho_{\mathrm{p}, \mathrm{RS}}(\lambda)$ through curve fitting. It would be possible to examine the magnitude of $\varepsilon(f, \lambda)$ from measurements of $L_{\mathrm{ds}} / L_{\mathrm{ds}, 0}$ for the range of $f$ values, using an underwater spectroradiometer (e.g., Potes et al., 2013). Experimentally derived $\varepsilon(f$, $\lambda$ ) and $\rho_{\mathrm{p}, \mathrm{Rs}}(\lambda)$ represent the plastic objects shape and not just apply for a single flat layer of plastic. The sample site should be clear water as in turbid waters it will be harder to see a plastic signal (Section 2.2).

\subsubsection{Laboratory}

Reflectance and transmittance of the plastic measured in the laboratory (in a benchtop spectrometer, using the spectrometer with a contact probe, or using the spectrometer with a stable and calibrated light source) are not the same as, but related to $\rho_{\mathrm{p}, \mathrm{RS}}$ and $\tau_{\mathrm{p}}$ respectively. The relation between $\rho_{\mathrm{p}, \mathrm{RS}}\left(\tau_{\mathrm{p}}\right)$ derived from the field observations and measured reflectance (transmittance) can clarify how the shape of a plastic object and the composition of natural daylight affect $\rho_{\mathrm{p}, \mathrm{RS}}\left(\tau_{\mathrm{p}}\right)$ The laboratory measurements will help select wavelengths for which plastic reflectance is high and -transmittance low and will add to the spectral library of the spectrum characteristic of plastic debris types, which will be very valuable to the marine plastics science community (Maximenko et al., 2016).

\subsubsection{Satellite remote sensing}

Emberton et al. (2016) give an overview of satellite based multispectral and hyperspectral ocean colour remote sensors of the past, present and future. Satellites that carry ocean colour sensors usually carry other instruments that are useful for marine plastic detection. For example the OLCI ocean colour instrument with 21 bands in the VISNIR $(0.4-1.02 \mu \mathrm{m})$ on Sentinel-3 works in synergy with Sentinel-3's SLSTR instrument comprising nine bands in the VIS-SWIR 0.55-12 $\mu \mathrm{m}$ (ESA, 2017). It will be interesting to see if satellite measurements in the spectral bands of our choice applied to our reflectance model can replicate the global distribution of marine plastics calculated by various particle-tracking models (e.g., van Sebille et al., 2012, 2015) and ocean surveys (Eriksen et al., 2014; Cózar et al., 2017). Of special interest are the "hot spots" of marine plastics such as the centres of the subtropical gyres predicted by these models but never seen from space before. The biggest hotspot of all is located in the North Pacific between Hawai'i and California (Law et al., 2014). Hard to reach areas, such as the Arctic, could really benefit from RS observations. Floating plastic accumulation is predicted in the Arctic (van Sebille et al., 2012) but this region of the ocean is difficult to survey extensively (Cózar et al., 2017). However, the most common atmospheric correction method is the black pixel approach, which assumes that water-leaving radiance, $L_{\mathrm{wt}}$, is equal to zero in the NIR or SWIR so that the measurements taken from a band in one of these regions only contain aerosol atmospheric and ocean surface effects. This correction would therefore likely conceal the signal in the NIR and SWIR from plastic in the ocean and we would need the uncorrected data. An alternative atmospheric and sun glint correction algorithm, POLYMER, derives ocean colour parameters in the whole sun glint spectrum and does not require negligible water reflectance in near infrared bands (Steinmetz et al., 2011). POLYMER is based on a model, extended from $700 \mathrm{~nm}$ to $900 \mathrm{~nm}$ by using the similarity spectrum for turbid waters (Ruddick et al., 2006), which may remove optical signal from sea surface plastic. Oceanic whitecaps are reflective in the solar spectral range (Koepke, 1984) and therefore capable of corrupting the marine plastic signal. We therefore recommend the use of satellite data for marine plastic estimations under low wind speed conditions; whitecapping is negligible when the wind speed is $<3$ or $4 \mathrm{~ms}^{-1}$ (Goddijn-Murphy et al., 2011). Wave height and wind over the ocean can be estimated from radar altimetry, for example the SRAL altimeter on board Sentinel-3 (ESA, 2017). 


\section{Conclusion}

We have a presented an optical reflectance model that can be used as a first step towards a remote sensing algorithm for marine plastic litter. There are many types of marine plastic litter and we have considered floating macroplastics of one type for simplicity. If we know RS reflectance of the clear sea surface, $R_{\mathrm{w}, 0}(\lambda)$, and of the plastic, $\rho_{\mathrm{p}, \mathrm{RS}}(\lambda)$, we can estimate the fraction of plastic surface area from measurements in air. We can approximate $R_{\mathrm{w}, 0}(\lambda)$ if the water type is known (e.g., Moore et al., 2014; Mélin and Vantrepotte, 2015), and derive $\rho_{\mathrm{p}, \mathrm{RS}}(\lambda)$ from the proposed field measurements, or they could be used as tuning parameters. It may be necessary to account for shading of surface plastic, i.e., reduced subsurface light due surface plastic blocking downwelling sunlight. Key is to select a wavelength for which water leaving light is minor and plastic reflectance is high, for example around $750 \mathrm{~nm}$, (single band algorithm), or two wavelengths for which water reflectance is near equal and the reflectance of the plastic is not (dual band algorithm).

\section{Acknowledgements}

This work was made possible by the Carnegie Trust, Research Incentive Grant (70649). In addition, the ERDF Interreg VB Northern Periphery and Arctic (NPA) Programme funded this activity through the Circular Ocean project. Erik van Sebille was supported through funding from the European Research Council (ERC) under the European Union's Horizon 2020 research and innovation programme (grant agreement No 715386).

\section{Appendix A. Computation of the spectral shading factor}

The relationship between $\varepsilon$ and $f$ can be predicted using the same optical model as for modelling light reflectance in air (Section 2.2). The expression corresponding to Eq. (1) is,

$L_{\mathrm{ds}}(\lambda)=(1-f) L_{\mathrm{ds}, 0}(\lambda)+f L_{\mathrm{ps}}(\lambda)$

with $L_{\mathrm{ps}}$ subsurface downwelling plastic leaving radiance. In analogy with Eq. (2), we describe $L_{\mathrm{ps}}$ as,

$L_{\mathrm{ps}}=\tau_{\mathrm{pw}} L_{\mathrm{d}}+\rho_{\mathrm{pw}} L_{\mathrm{ws}}$

with $\tau_{\mathrm{pw}}$ the fraction of downwelling light in air transmitted through the plastic object into the water, and $\rho_{\mathrm{pw}}$ the subsurface reflectance at the waterplastic interface. Using $\varepsilon(f, \lambda)=L_{\mathrm{ds}} / L_{\mathrm{ds}, 0}=L_{\mathrm{ws}} / L_{\mathrm{ws}, 0}, L_{\mathrm{ws}}=r_{\mathrm{ws}} L_{\mathrm{ds}}$, and $\tau_{\mathrm{w}}=L_{\mathrm{d}} / L_{\mathrm{ds}, 0}$, it can be shown that

$\varepsilon(f, \lambda)=\frac{1-f\left(1-\tau_{p w}(\lambda) / \tau_{w}(\lambda)\right)}{1-f \rho_{p w} r_{w s}}$

\section{References}

Andrady, A.L., 2015. Persistence of plastic litter in the oceans. In: Bergmann, M., Gutow, L., Klages, M. (Eds.), Marine Anthropogenic Litter. Springer International Publishing AG Switzerland, Springer Open. http://dx.doi.org/10.1007/978-3-319-16510-3.

Andrady, A.L., Neal, M.A., 2009. Applications and societal benefits of plastics. Philos. Trans. R. Soc. Lond. Ser. B Biol. Sci. 364, 1977-1984.

Asner, 2016. Workshop on mission concepts for marine debris sensing, January 19-21, 2016, east-west center of the university of Hawaii at Manoa, Honolulu, Hawaii. available online. http://iprc.soest.hawaii.edu/NASA_WS_MD2016/pdf/Asner2016. pdf, Accessed date: 8 September 2017.

Austin, R.W., 1980. Coastal Zone Color Scanner Radiometry, Proc. SPIE 0208, Ocean Optics VI, 170 (March 26, 1980). http://dx.doi.org/10.1117/12.958273.

Cózar, A., Martí, E., Duarte, C.M., García-de-Lomas, J., van Sebille, E., Ballatore, T.J., et al., 2017. The Arctic Ocean as a dead end for floating plastics in the North Atlantic branch of the thermohaline circulation. Sci. Adv. 3, e1600582. http://advances. sciencemag.org/cgi/content/full/3/4/e1600582/DC1.

Dekker, A.G., 1990. Detection of Optical Water Quality Parameters for Eutrophic Waters by High Resolution Remote Sensing. PhD Thesis. Vrije Universiteit, Amsterdam.

Dobretsov, S., Thomason, J.C., Williams, D.N., 2014. Biofouling Methods. England, John Wiley \& Sons, Ltd., West Sussex.

Driedger, A.G.J., Dürr, H.H., Mitchell, K., Van Cappellen, P., 2015. Plastic debris in the Laurentian Great Lakes: a review. J. Grate Lakes Res. 41 (1), 9-19. http://dx.doi.org/ 10.1016/j.jglr.2014.12.020.

Emberton, S., Chittka, L., Cavallaro, A., Wang, M., 2016. Sensor capability and atmospheric correction in ocean colour remote sensing. Remote Sens. 8, 1. http://dx.doi. org/10.3390/rs8010001.

Eriksen, M., Lebreton, L.C.M., Carson, H.S., Thiel, M., Moore, C.J., Borerro, J.C., Galgani, F., Ryan, P.G., Reisser, J., 2014. Plastic pollution in the world's oceans: more than 5 trillion plastic pieces weighing over 250,000 tons afloat at sea. PLoS One 9 (12), e111913. http://dx.doi.org/10.1371/journal.pone.0111913.

ESA, 2017. Sentinel online, user guides. available online. https://sentinel.esa.int/web/ sentinel/user-guides/, Accessed date: 8 September 2017.

Filella, M., 2015. Questions of size and numbers in environmental research on microplastics: methodological and conceptual aspects. Environ. Chem. 12 (5), 527-538. http://dx.doi.org/10.1071/EN15012.

Goddijn-Murphy, L., Woolf, D.K., Callaghan, A.H., 2011. Parameterizations and algorithms for oceanic whitecap coverage. J. Phys. Oceanogr. 41 (4), 742-756. http://dx. doi.org/10.1175/2010JPO4533.1.

Gordon, H.R., Brown, O.B., Jacobs, M.M., 1975. Computed relationships between the inherent and apparent optical properties of a flat homogeneous ocean. Appl. Opt. 14, 417-427.

Gregory, M.R., 2009. Environmental implications of plastic debris in marine settings-entanglement, ingestion, smothering, hangers-on, hitch-hiking and alien invasions. Philos. Trans. R. Soc. Lond. Ser. B Biol. Sci. 364 (1526), 2013-2025. http://dx.doi.org/10.1098/rstb. 2008.0265.

Hecht, E., Zajac, A., 1974. Optics. Addison-Wesley Publishing Company, Inc., Massachusetts.

Hobson, D.E., Williams, D., 1971. Infrared spectral reflectance of sea water. Appl. Opt. 10, 2372-2373. http://dx.doi.org/10.1364/AO.10.002372.

Irvine, W.M.J.B., Pollack, J.B., 1968. Infrared optical properties of water and ice spheres. Icarus 8.

Jambeck, J.R., Geyer, R., Wilcox, C., Siegler, T.R., Perryman, M., Andrady, A., et al., 2015. Plastic waste inputs from land into the ocean. Science 347 (6223), 768-771.

Jerlov, N.G., 1968. Optical Oceanography. Elsevier Publishing Company, Amsterdam.

Kirk, J.T.O., 1994. Light \& Photosynthesis in Aquatic Ecosystems. Cambridge University Press, Cambridge.

Koepke, P., 1984. Effective reflectance of oceanic whitecaps. Appl. Opt. 23 (11).

Laist, D.W., 1997. Impacts of marine debris: entanglement of marine life in marine debris including a comprehensive list of species with entanglement and ingestion records. In: Coe, J.M., Rogers, D.B. (Eds.), Marine Debris. Springer Series on Environmental Management. Springer, New York, NY.

Law, K.L., Morét-Ferguson, S.E., Goodwin, D.S., Zettler, E.R., DeForce, E., Kukulka, T., Proskurowski, G., 2014. Distribution of surface plastic debris in the eastern Pacific Ocean from an 11-year data set. Environ. Sci. Technol. 48, 4732-4738. http://dx.doi. org/10.1021/es4053076.

Maximenko, N., Arvesen, J., Asner, G., Carlton, J., Castrence, M., Centurioni, L., et al., 2016. Remote Sensing of Marine Debris to Study Dynamics, Balances and Trends. Community White Paper Produced at the Workshop on Mission Concepts for Marine Debris Sensing, January 19-21, 2016, East-West Center of the University of Hawaii at Manoa, Honolulu, Hawaii. (Submitted to: Decadal Survey for Earth Science and Applications from Space).

Mélin, F., Vantrepotte, V., 2015. How optically diverse is the coastal ocean? Remote Sens. Environ. 160, 235-251. http://dx.doi.org/10.1016/j.rse.2015.01.023.

Moore, T.S., Dowell, M.D., Bradt, S., Antonio Ruiz Verdud, A.R., 2014. An optical water type framework for selecting and blending retrievals from bio-optical algorithms in lakes and coastal waters. Remote Sens. Environ. 143, 97-111. http://dx.doi.org/10. 1016/j.rse.2013.11.021.

Morel, Y.A., Prieur, L., 1977. Analysis of variations in ocean color. Limnol. Oceanogr. 22 (4), 709-722.

Mrosovsky, N., Ryan, G.D., James, M.C., 2009. Leatherback turtles: the menace of plastic Mar. Pollut. Bull. 58 (2), 287-289.

Potes, M., João Costa, M., Salgado, R., Bortoloi, D., Serafim, A., Le Moigne, P., 2013. Spectral measurements of underwater downwelling radiance of inland water bodies. Tellus 65, 20774. http://dx.doi.org/10.3402/tellusa.v65i0.20774.

Rochman, C.M., Browne, M.R., Underwood, M.A., van Franeker, A.J., Thompson, J.A., Amaral-Zettler, R.C., 2016. The ecological impacts of marine debris: unravelling the demonstrated evidence from what is perceived. Ecology 97 (2), 302-312. http://dx. doi.org/10.1890/14-2070.1. 
Ruddick, K.G., De Cauwer, V., Park, Y.-.J., Moore, G., 2006. Seaborne measurements of near infrared water-leaving reflectance: the similarity spectrum for turbid waters. Limnol. Oceanogr. 51 (2), 1167-1179. http://dx.doi.org/10.4319/lo.2006.51.2. 1167.

Ryan, P.G., 2015. Does size and buoyancy affect the long-distance transport of floating debris? Environ. Res. Lett. 10, 084019. http://dx.doi.org/10.1088/1748-9326/10/8/ 084019.

Sherman, P., van Sebille, E., 2016. Modeling marine surface microplastic transport to assess optimal removal locations. Environ. Res. Lett. 11, 014006. http://dx.doi.org/ 10.1088/1748-9326/11/1/014006.

Steinmetz, F., Deschamps, P.-.Y., Ramon, D., 2011. Atmospheric correction in presence of sun glint: application to MERIS. Opt. Express 19, 9783-9800. http://dx.doi.org/10. 1364/OE.19.009783.

van Sebille, E., England, M.H., Froyland, G., 2012. Origin, dynamics and evolution of ocean garbage patches from observed surface drifters. Environ. Res. Lett. 7, 044040. http://dx.doi.org/10.1088/1748-9326/7/4/044040.

van Sebille, E., Wilcox, C., Lebreton, L., Maximenko, N.A., Hardesty, B.D., van Franeker, J.A., et al., 2015. A global inventory of small floating plastic debris. Environ. Res. Lett. 10 (12), 124006. http://dx.doi.org/10.1088/1748-9326/10/12/124006.

Wilcox, C., Van Sebille, E., Hardesty, B.D., 2015. Threat of plastic pollution to seabirds is global, pervasive, and increasing. PNAS 112 (38), 11899-11904. http://dx.doi.org/ 10.1073/pnas.1502108112 